Earth's crust in the Antaretic continent are presented by G. E. Lazarev and S. A. Ushakov (Priroda, 12, 17 ; 1960). These results show that in the eastern Antarctic the average thickness of the ice sheet is not less than $2,000 \mathrm{~m}$. and its maximum thickness $4,000 \mathrm{~m}$. The level of the rock surface below the ice sheet varies from $1,000 \mathrm{~m}$. above sea-level to $800 \mathrm{~m}$. below sea-level. The thickness of the Earth's crust (above 'Moho') is $5-10 \mathrm{~km}$. for the oceanic type, and $25-70 \mathrm{~km}$. for the continental type. The average density of the crust is $\mathbf{2 \cdot 8}$. The result of the gravity work is also discussed and it is suggested that the ice load produces a sag in the crust of the order of 600-700 m.

\section{Singing Sand}

As the result of deepening the channel of the River Dnieper below the town of Kremenchug a small artificial island of sand was formed. This sand, as described by G. G. Velikii (Priroda, 6, 82; 1960), when trodden on emits a singing sound. Neither very dry nor very wet sand will 'sing'. As a rule the sand emits a high pitch in the morning and a lower pitch towards the evening. The 'singing sand' from the Dnieper may thus be compared with the 'musical sand' from the Isle of Eigg in Scotland and other localities.

\section{Rabies in India}

THE prevalence of rabies in India is indicated in the report of the Director of the Pasteur Institute of Southern India, Coonoor, for 1959 (Pp. i+116. Coonoor: Pasteur Institute, 1960). During the year, 34,239 courses of anti-rabies vaccine were issued. Of the 35,403 patients treated at the Institute and subsidiary treatment centres during the year, case cards were returned for 15,447 patients. Of these, 9,007 received a complete course of treatment. During the year 980 patients received a complete course of anti-rabies treatment at the Institute itself (968 Asiatics and 12 Europeans). An incomplete course of treatment was also given to 184 patients (Asiatics) of whom 52 were absolved from further treatment after the possibility of rabies in the biting animals had been excluded. One death was recorded among the 1,164 patients who received complete or incomplete courses of treatment giving a mortality. rate of 0.08 per cent. During the period 1907-59, the total number of patients treated at the Institute was 47,197, among whom 417 later died of rabies giving a mortality-rate of 0.88 per cent. Equally encouraging figures are shown by the subsidiary centres where, in 1959, the number of deaths among 8,027 patients who received a complete course of treatment had fallen to $12(0 \cdot 15$ per cent). Anti-rabies treatment was also made available for the prophylactic treatment of animals. During the 37-year period from 1923 to $1959,51,382$ animals have received anti-rabies treatment, among which 473 deaths have been reported, giving a mortality-rate of 0.92 per cent. The report also describes the routine work and fundamental research into the nature of other diseases carried out at the Pasteur Institute.

Isolation of Malignolipin from Malignant Tumours

KOSAKI and his co-workers isolated a new phospholipid, malignolipin, from human malignant tumours on the basis of its affinity for porphyrin, and found that it was composed of choline, spermine, phosphoric acid and fatty acid; was specific to malignant tumours; and that it promoted intra. peritoneal growth of Ehrlich's ascites cancer. A large amount of malignolipin is needed to establish the structure of this compound, and to reveal its biological and, especially, pathophysiological significance. The method previously described was not suitable for extracting malignolipin in large quantities and, recently, Kosaki and his colleagues have described how the substance can be produced in considerably increased quantities (Mie Med.J., 10, No. 2 ; August 1960). The investigation makes clear that malignolipin is a phospholipid which has not previously been isolated. Two other articles in the same journal also deal with malignolipin. One indicates a method for detecting and measuring the substance in various tissues including blood and escites and the other describes the column chromatographic isolation of malignolipin.

\section{Trapping of Plasma by Red Cells}

AN accurate method for dividing red-blood cell columns has been devised by Peggy Clark and B. J. Walsh of the New South Wales Red Cross Blood Transfusion Service, Sydney (Austral. J. Exp. Biol. and Med. Sci., 38, Part 6; Dec. 1960). Blood is placed in polyvinyl chloride tubing which is sealed at one end with a glass bead. This tubing is inserted into a piece of glass tube before centrifugation, and later the contents can be frozen before the tubing is divided. The method was used to measure the amount of plasma trapped with the red blood cells. From these measurements the ratio of the true to the observed hrmatocrit value was found to be 0.94 at centrifugal forces greater than $1,430 \mathrm{~g}$. The ratio decreased with decreasing relative centrifugal force, but variations in the hæmatocrit value did not alter the correction factor. The amount of plasma trapped in the centrifuged and sedimented normal human blood decreased from top to bottom of the red-cell columns, but the amount in different sections of the columns became uniform as the time of centrifugation or of sedimentation increased. A blood sample with a high sedimentation-rate showed a different pattern on sedimentation.

\section{Leverhulme Research Awards}

THE following fellowships and research grants tenable for periods up to two years have been announced: Fellowships, Dr. A. M. Dunn, lecturer in veterinary parasitology, University of Glasgow, for work on the parasitic helminth fauna of wild ruminants in Britain; P. Haggett, University demonstrator in geography, University of Cambridge, for work on secular changes in the forested area of the Serra do Mar, Brazil, 1814-1962; Dr. R. P. A. Sneeden, lecturer in chemistry, University of Glasgow, for investigations on the structures of large-ring antibiotics; Dr. L. E. Sutton, demonstrator in physical chemistry, University of Oxford, for studies on the significance of molecular shapes and sizes. Research grants, N. S. Angus, chief metallurgist, the Production Engineering Research Association, Melton Mowbray, for a metallurgical and chemical examination of samples of early iron and steel; E. G. Bowen, professor of geography and anthropology, University of Wales, Aberystwyth, for studies on the historical geography of the early Christian period in Celtic Europe; J. Heath, of the Nature Conservancy, Grange-over-Sands, for taxonomic and biological studies of the Micropterygidae and Eriocraniidae; 